\title{
Minimally invasive spine technology and minimally invasive spine surgery: a historical review
}

\author{
Jeffrey H. Oppenheimer, M.D., ${ }^{1}$ Igor DeCastro, M.D., ${ }^{2}$ and Dennis E. McDonnell, M.D. ${ }^{1}$ \\ ${ }^{1}$ Division of Neurosurgery, Department of Surgery, Central Arkansas Veterans Hospital; \\ and ${ }^{2}$ Division of Neurosurgery, University of Arkansas for Medical Sciences, Little Rock, Arkansas
}

\begin{abstract}
The trend of using smaller operative corridors is seen in various surgical specialties. Neurosurgery has also recently embraced minimal access spine technique, and it has rapidly evolved over the past 2 decades. There has been a progression from needle access, small incisions with adaptation of the microscope, and automated percutaneous procedures to endoscopically and laparoscopically assisted procedures. More recently, new muscle-sparing technology has come into use with tubular access. This has now been adapted to the percutaneous placement of spinal instrumentation, including intervertebral spacers, rods, pedicle screws, facet screws, nucleus replacement devices, and artificial discs. New technologies involving hybrid procedures for the treatment of complex spine trauma are now on the horizon. Surgical corridors have been developed utilizing the interspinous space for X-STOP placement to treat lumbar stenosis in a minimally invasive fashion. The direct lateral retroperitoneal corridor has allowed for minimally invasive access to the anterior spine.

In this report the authors present a chronological, historical perspective of minimal access spine technique and minimally invasive technologies in the lumbar, thoracic, and cervical spine from 1967 through 2009. Due to a low rate of complications, minimal soft tissue trauma, and reduced blood loss, more spine procedures are being performed in this manner. Spine surgery now entails shorter hospital stays and often is carried out on an outpatient basis. With education, training, and further research, more of our traditional open surgical management will be augmented or replaced by these technologies and approaches in the future. (DOI: 10.3171/2009.7.FOCUS09121)
\end{abstract}

\section{KEY WORDS - history of surgery - minimally invasive spine surgery • surgical technology $\quad$ endoscope $\quad$ laparoscope $\bullet \quad$ image guidance}

A BASIC tenet of surgery is to effectively treat pathology with minimal disturbance of normal anatomy: leaving "the smallest footprint." This is being accomplished more effectively by designing procedures that require smaller incisions, result in less soft-tissue disruption, and involve limited surgical corridors. The development of these procedures has been implemented through technological advances in illumination, magnification, and instrumentation. Most surgical specialties

\footnotetext{
Abbreviations used in this paper: $\mathrm{ACDF}=$ anterior cervical discectomy and fusion; $\mathrm{AD}=$ aggressive discectomy; $\mathrm{ADR}=$ artificial disc replacement; $\mathrm{ALIF}=$ anterior lumbar interbody fusion; $\mathrm{APLD}=$ automated percutaneous lumbar discectomy; $\mathrm{BMP}=$ bone morphogenetic protein; CAVHS = Central Arkansas Veterans Healthcare System; DLIF = direct lateral interbody fusion; IDET = intradiscal electrothermy; LD = limited discectomy; LPD = laser-assisted percutaneous discectomy; MAST = minimal access spinal technique; MED = microendoscopic discectomy; MIS = minimally invasive surgery; $\mathrm{PEEK}=$ polyetheretherketone; $\mathrm{PLIF}=$ posterior lumbar interbody fusion; rhBMP-2 = recombinant human BMP-2; TLIF = transforaminal interbody fusion; XLIF = extreme lateral interbody fusion.
}

have embraced this minimalist concept, particularly general surgery, with a dramatic rise in the numbers of laparoscopic cholycystectomies. ${ }^{74,90}$ Spine surgery is also gaining momentum in this regard, although some reports suggest that the limited exposure that results from these techniques can result in incomplete treatment of pathology with no clear-cut advantage over traditional techniques. ${ }^{39,60,79,112}$ The avoidance of complications is more challenging through limited surgical portals. Recurrence and reoperation rates can increase, especially in the realm of lumbar disc surgery. In spite of these challenges, the evolution of minimal access spine technique (MAST) has exceeded that of traditional spine procedures over the past 2 decades (Fig. 1). This began with Yaşargil's adaptation of the operating microscope to lumbar discectomy in $1967 . .^{135}$ With the advent of managed care, the diagnostic related group (DRG) system, and efforts to return patients to work more quickly, there has been pressure to perform spine procedures on an outpatient basis or with very short hospital stays. Spine center models developed and frequently use these techniques in their efforts to deliver a higher level of care efficiently. Additionally, 


\section{J. H. Oppenheimer, I. DeCastro, and D. E. McDonnell}
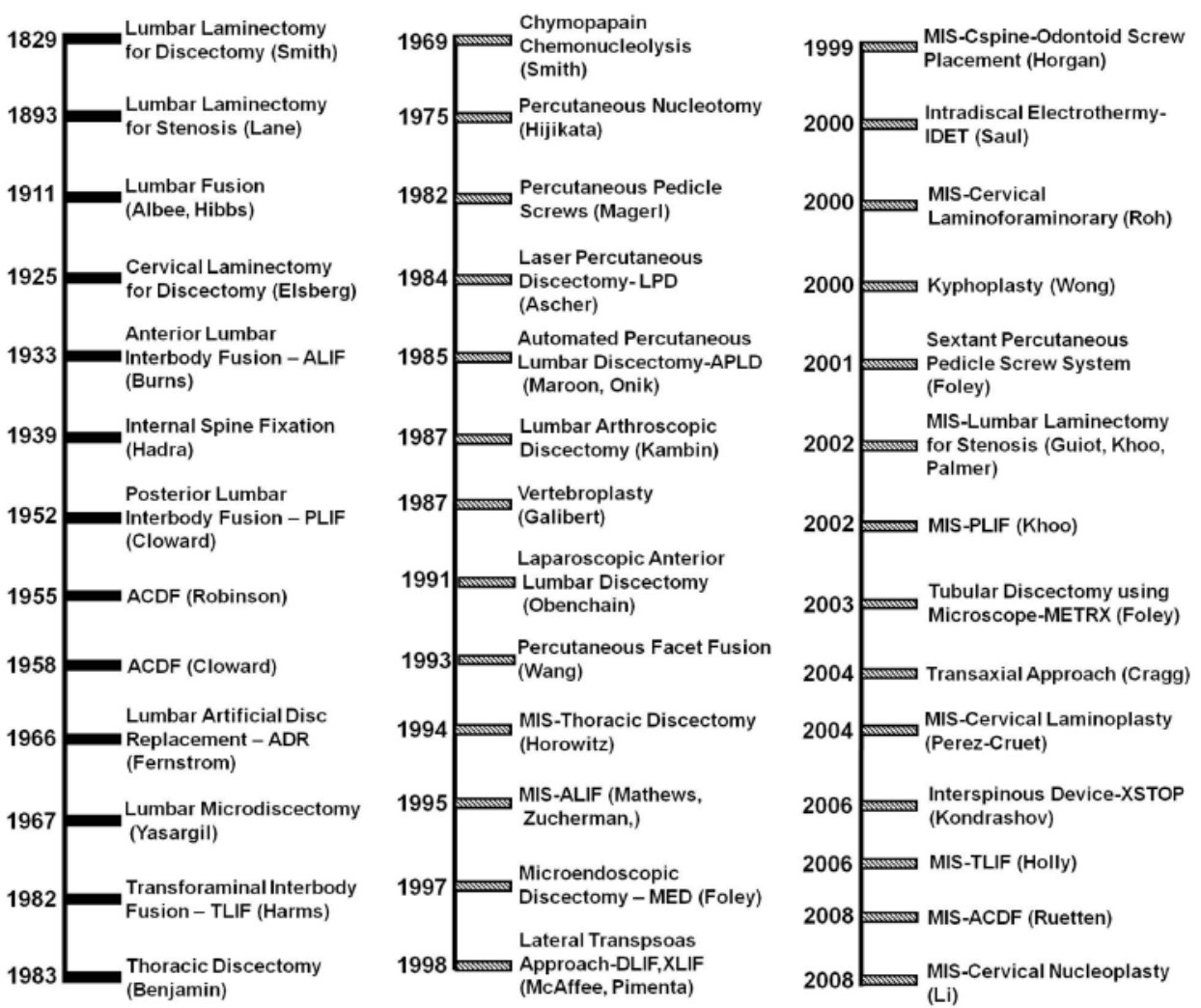

FIG. 1. Chronological timelines showing technical and procedural milestones in spine surgery using traditional techniques (first column) and MAST (second and third columns).

telemedicine and the availability of Internet access to the medical consumer have increased the public demand for these procedures. Consequently, more spine surgeons are seeking training and proficiency in these techniques. The purpose of this article is to document the history, present status, controversies, and future trends in minimally invasive spine surgery and its associated technologies. Discussion will be limited to disc pathology and degenerative and traumatic disorders in the various regions of the spinal column.

\section{Lumbar Disc Disease}

Historical reviews document that the first laminectomy was performed in the US for traumatic disc rupture in 1829 by A. G. Smith. ${ }^{68,106}$ Oppenheim and Krause ${ }^{96}$ reported successful removal of a ruptured disc as early as 1909. The first unilateral laminectomy was performed in cadavers by Taylor. ${ }^{99}$ Mixter and Barr ${ }^{88}$ are credited with our earliest understanding of lumbar disc disease in 1934. One of the earliest milestones in the development of minimally invasive spine surgery and, in particular, lumbar disc surgery, dates back to 1941 with the discovery of chymopapain. Jansen and Balls ${ }^{57}$ discovered that properties of the Carica papaya fruit could cause depolymerization of the proteoglycan and glycoprotein macromolecules in the nucleus pulposus. Smith adapted these laboratory concepts to the clinical setting and performed the first chemonucleolysis procedures in humans in 1969 , and this is considered to be the first minimally invasive spine procedure. ${ }^{120}$ It involved a needle technology whereby the chemical chymopapain was injected into the annulus to remove the herniated disc by enzymatic hydrolysis. In spite of its eventual approval by the FDA, enthusiasm for this procedure has dwindled, as several reports of arachnoiditis and other associated complications were published. ${ }^{8,89,121}$ Descriptions of a 3- to 4-month history of low-back pain from chemical discitis were not uncommon in the postoperative course of these patients. In 1975 the first percutaneous nucleotomy technique was reported by Hijikata. ${ }^{48}$ Open lumbar microdiscectomy was popularized 3 years later by Williams ${ }^{132}$ with his technological advances that allowed soft-tissue retraction through a small surgical corridor. Laser-assisted percutaneous discectomy was first reported in $1984,{ }^{7}$ and the nucleotome was developed in animal models by Onik and colleagues. ${ }^{95}$ Principles of its mechanism involved rhythmic irrigation, pulsation, aspiration and cutting to retrieve the disc from inside the annulus. Kambin is credited with the first percutaneous lumbar discectomy and this was assisted by fluoroscopy in 1987. ${ }^{59}$ Maroon ${ }^{80}$ in 1987, first reported the clinical use of the nucleotome in a procedure called automated percutaneous lumbar discectomy (APLD). Many of these procedures were indicated only for contained disc pathology rather than disc extrusions, sequestrations, or spondylotic nerve root compression. The efficacy of many of these techniques compared with standard disc removal still remains in question. 


\section{Minimally invasive spine technology and surgery}

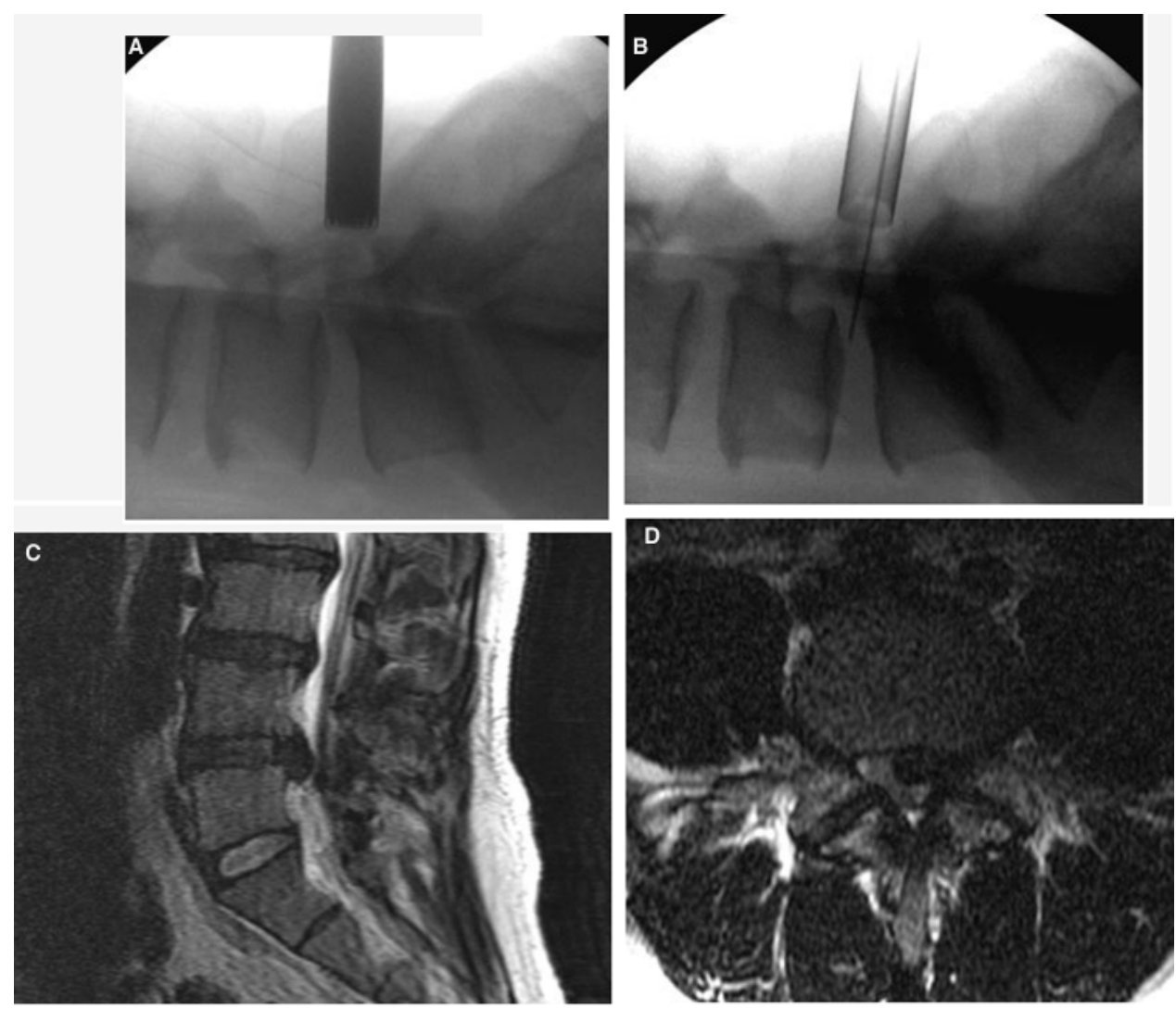

FIG. 2. Images illustrating the MIS lumbar discectomy technique. This case involved a 38-year-old patient who underwent removal of a large L4-5 left centrolateral disc extrusion. A and B: Intraoperative lateral fluoroscopic images showing dilators in place $(A)$ and documentation of intended level of surgery using an 18-gauge spinal needle through a 14-mm METRx retractor (B). C and D: Preoperative MR images.

Tubular access to the lumbar disc was first reported by Faubert and Caspart ${ }^{31}$ in 1991 and this led to the way for development of tubular retractor systems and low profile instruments. The first report of the microendoscopic discectomy (MED) procedure came from Foley and Smith in 1997. ${ }^{34}$ The learning curve for these techniques was steep with significant unintended durotomy rates, which limited their initial popularity. ${ }^{87,92,100}$ Nevertheless, orthopedic spine surgeons quickly embraced these techniques due to their greater familiarity with the arthroscope in joint surgery. However, with the adaptation of the microscope to the use of tubular retractors in 2003, the METRx system (Medtronic, Inc.), more neurosurgeons implemented these techniques. The theory behind these procedures is to lessen the pain and morbidity of disc access by effectively sparing the muscles. With fluoroscopic assistance, the paraspinal muscles directly in line with the disc space on the symptomatic side are sequentially dilated-rather than being dissected and denuded off the lamina. Once this is done, a tubular retractor is placed over the dilators. The dilators are removed and the microscope is directed to visualize the lamina and interspace to allow bone and subsequent disc removal with minimal muscular trauma. Tubular retractors can also be directed over the dorsolateral aspects of the posterior elements, and with aid of the microscope this can be a very effective surgical option for far-lateral disc herniation when compared with the tradi- tional open intermuscular or facetectomy approaches. ${ }^{42,94}$ A more recent technological development in MAST procedures for the treatment of lumbar disc pathology is intradiscal electrothermy (IDET). This technique was introduced in 2000 by Saal and Saal. ${ }^{114,115}$ The popularity of IDET was limited due to lack of clinical trials and long-term outcome data. This created an environment where very few carriers allowed preauthorization for its use, thereby eliminating reimbursement for IDET.

The use of MAST remains controversial in the management of lumbar disc disease as there are still no established guidelines for the surgical treatment of this entity. Not only is there disagreement on whether minimally invasive access versus more traditional, open access is appropriate in the management of these cases but also whether disc removal itself should be limited or aggressive. ${ }^{10,11}$ Limited discectomy (LD) involves retrieval of extruded disc material and intradiscal fragments that are loose and can be easily removed using pituitary rongeurs. Disc material may or may not be in contact with the thecal sac or descending or exiting nerve roots. The rationale for limited disc removal is to preserve the disc and maintain stability and motion. Aggressive discectomy (AD) involves curettage and removal of not only the protruded, extruded, or sequestered disc material but also thorough evacuation of the "parent disc." Recent studies ${ }^{20,86,131}$ comparing the 2 techniques suggest that recurrence rates in 


\section{J. H. Oppenheimer, I. DeCastro, and D. E. McDonnell}

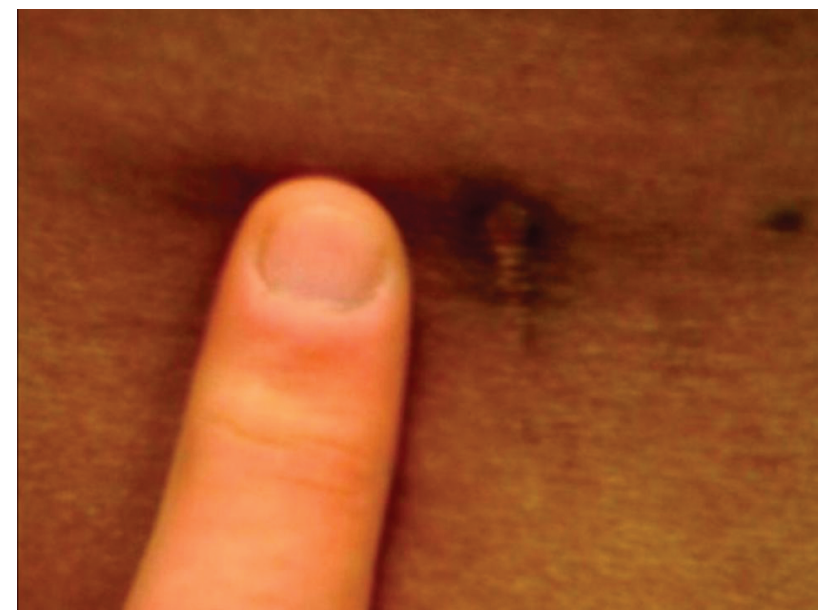

FIG. 3. Photograph showing the MIS L4-5 discectomy incision (7 $\mathrm{mm})$ in the patient in Fig. 2 at 6 weeks after surgery.

patients who have undergone LD tend to be higher in the initial 6 months following surgery. At 24 months, however, delayed radiculopathy and low-back pain are more frequent in those who have undergone AD. These latter symptoms are felt to be due to foraminal narrowing and disc space collapse. Some surgeons favor LD, as the early recurrences seen after this procedure are easier to manage than the delayed symptoms seen after AD. This is due to the fact that surgery for recurrent disc herniation involves reexploration of the laminectomy site with disc retrieval, whereas management of radiculopathy and lumbago due to disc collapse due to AD often involves arthrodesis, instrumentation, or artificial disc replacement-all of which represent a much greater undertaking.

Even within our own department at CAVHS, there are differences in the surgical management of lumbar disc disease. The senior author (D.E.M.) will typically perform open $\mathrm{AD}$ type procedures with aggressive use of curettes on the end plates, similar to what would be performed in preparation for interbody fusion. The primary author (J.H.O.) uses METRx tubes to perform discectomies for first-time herniations (Figs. 2 and 3). Typically $\mathrm{LD}$ is performed in these cases, but $\mathrm{AD}$ is used for recurrent herniations to avoid any subsequent need for disc reexploration. Methods include the preoperative selection of tube diameter (range 14-26 mm). After sequential dilation is completed, a depth measurement is taken from skin to lamina by reading off a gauge on the side of the largest dilator, and the appropriate retractor length is selected. The retractor is fixed to the operating table using a flexible arm attached to a vice clamp. The dilators are then removed and the microscope is directed through the retractor. If the tube position needs to be changed, the largest previously used dilator is reinserted into the retractor and the flexible arm is temporarily loosened. This effectively allows the dilator to act as lever arm to change the distal position of the tube and has been referred to as "wanding." This technique allows the surgeon complete disc access in addition to the ability to perform foraminotomies over both the exiting and descending nerve roots. In our experience, MAST is better tolerated than open approaches to the lumbar disc. However, the relative increase in pain from aggressive removal of disc from the end plates (AD) when compared to the LD approach can nullify the advantages of tubular access.

\section{Lumbar Spinal Stenosis}

The concept of classic open decompressive lumbar laminectomy for the treatment of spinal stenosis dates back to 1893 when the procedure was performed by Lane. ${ }^{71}$ The first to report the unilateral approach for bilateral spinal canal decompression were Young et al. ${ }^{136}$ in 1988. Development of this surgical corridor requires the removal of bone from the ipsilateral spinolaminar junction. The microscope is then utilized to visualize across the midline, and access is achieved to the contralateral recess of the spinal canal. Minimal access spinal technique was first adapted to this approach using METRx tubes, and this was reported independently by Fessler's group ${ }^{44,63}$ and by Palmer et al. ${ }^{97}$ in 2002. Enhanced visualization is achieved by combining the use of a microscope that allows multidirectional movement (such as the Contraves [Zeiss]), wanding the tubular retractor, and side-tilting the operating table. In our experience, up to 2 segments can be decompressed through a single unilateral paramedian incision using this technique (Fig. 4).

The most recent MAST in the treatment of lumbar stenosis is the X-STOP Interspinous Process Decompression System (St. Frances Medical Technologies, Inc.). This was first reported by Kondrashov and colleagues in 2006 for treatment of 1- or 2-level disease below L2-3 with good results. ${ }^{69}$ The main clinical criterion for selecting patients for this procedure is neurogenic claudication that is relieved by flexion..$^{73}$ The procedure can be performed under local anesthesia with the patient in the lateral position. It is a minimally invasive technique involving 2 small paramedian incisions. Once access is achieved, a distractor is placed between the superior and inferior spinous processes straddling the disc space of the stenotic segment. Once spinous process separation is optimized, a permanent spacer is selected based on readings of a gauge that is read off the distraction tool. Sizes are $8,10,12$, or $14 \mathrm{~mm}$ in diameter. Optimum position of the implant is in the midline at the spinolaminar junction. The X-STOP procedure effectively increases neural foraminal diameters indirectly by the divergent splaying of the spinous processes. ${ }^{105,119}$ Placement of the implant is straightforward and typically requires minimal operative time because it involves a region of the spine with familiar anatomy, easy access, and low risk. This procedure is gaining popularity, as results thus far have been very promising with very low complication rates reported. ${ }^{22,54,70}$ Should the device dislodge or fail to relieve symptoms, it can be safely removed, and other options such as decompression are still available. Placement of an X-STOP implant is a minimally invasive spine procedure that has the potential to broaden the operative management of spinal stenosis to a larger population of elderly patients whose comorbidities might otherwise have excluded them from the potential benefits of surgical treatment (Fig. 5). Spinous process fracture and implant dislodgment are recognized 


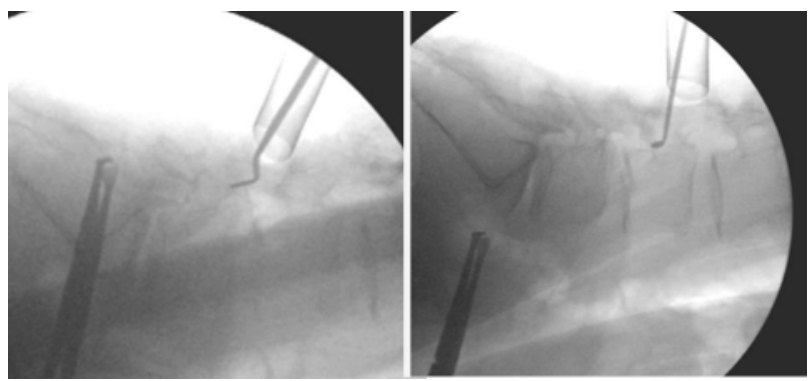

FIG. 4. Intraoperative lateral fluoroscopic images demonstrating wanding technique used to perform MIS L3-4 and L4-5 decompression. This patient was a 65 -year-old woman with a history of neurogenic claudication secondary to L3-4 and L4-5 stenosis. She went home symptom free 2 hours after surgery.

complications of the procedure. A PEEK form of the device, released in 2008, should lessen these complications, but clinical results have yet to be reported. It is anticipated to have good load-sharing properties, which would allow placement of an X-STOP implant in osteoporotic patients.

\section{Degenerative Disease of the Lumbar Spine}

Historical advances in imaging, spinal instrumentation, and bone graft substitutes have allowed development of both MAST and open procedures for not only fusion but also motion preservation in the treatment of lumbar degenerative disease. Early historical milestones that have profoundly impacted the open surgical management of arthritic spine conditions include the invention of the radiograph by Roentgen in $1895,{ }^{40}$ followed by development of the fluoroscope by Edison in $1896 .{ }^{61}$ Intraoperative spine imaging was reported as early as 1982 with use of real-time sonography for the localization of spinal cord cystic lesions. ${ }^{27}$ Hounsfield ${ }^{53}$ announced the invention of the CT scanner in 1972, and this technology has recently been adapted to $2 \mathrm{D}$ and $3 \mathrm{D}$ imaging platforms such as the Iso-C3D (Siemens AG) in 2004, ${ }^{52}$ and the $O$ arm (Medtronic Navigation, Inc.) released in 2005 but yet to be reported. These machines, which are essentially portable CT scanners, can provide $2 \mathrm{D}$ or $3 \mathrm{D}$ imaging and have features that allow for quick initial registration; they significantly limit radiation exposure for the operating room personnel, patient, and surgeon and are excellent adjuvants to MAST. In 1995, image guidance technologies were first used to perform spine surgery-by Pollack in the cervicomedullary junction ${ }^{103}$ and by Nolte for the placement of pedicle screws. ${ }^{91}$ The first spinal instrumentation procedure is credited to Hadra, who used wires to repair a spinous process fracture in $1891 .{ }^{45}$ The concept of bone augmentation and arthrodesis for the treatment of lumbar degenerative disc disease dates back to 1911, and successful fusions are documented in independent reports by Albee $^{2}$ and Hibbs. ${ }^{47}$ Kleinberg was a pioneer of the concept of using bone graft for fusion and reported this in $1922 .{ }^{66}$ Internal fixation as an adjuvant to the procedure was first described by Venable and Stuck in 1939. ${ }^{127}$ Over the past 50 years, allograft and bone substitutes have been developed, and this has facilitated the growth of minimally invasive procedures beginning with Cloward's use

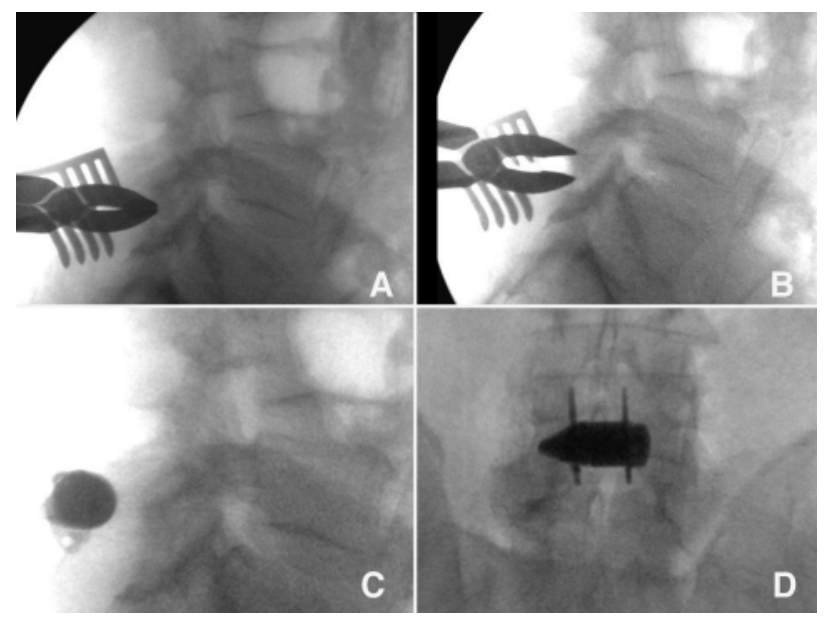

FIG. 5. Intraoperative lateral $(A-C)$ and anteroposterior (D) fluoroscopic images demonstrating the technique of interspinous (X-STOP) device placement. The patient was a 71-year-old man with a history of neurogenic claudication relieved by sitting. He was discharged on his first postoperative day following X-STOP placement and was walking 50 yards with an erect posture, pain free. A: Interspinous spreader placed between the spinous processes of $\mathrm{L}-4$ and $\mathrm{L}-5$. B: Distraction achieved. C and D: Final implant position.

of fresh frozen cadaver ileum dowels for anterior cervical fusion in $1958 .^{24}$ Graft site morbidity, particularly pain, has driven the development of allograft harvest and production, and these technologies have culminated in the discovery and use of genetically engineered products that contain purified bone growth factors.

Much of the developmental trends in MAST and in spine surgery in general have been driven by the challenge of achieving arthrodesis in the lumbar spine. This is true in the realms of spinal instrumentation, artificial disc replacement (ADR) technologies, and bone graft substitutes. An early illustration of this was the frequent utilization and, arguably, overuse of the interbody cage seen in the early 1990 s that many still refer to as the "cage rage." The discovery of bone morphogenetic protein (BMP) and its use might be considered another example of this. The development of these substances marks the culmination of 20 years of laboratory research and clinical trials and has undergone several FDA approvals. The development of BMP is considered one of the most studied and published advances in the history of orthopedics. ${ }^{84}$ Urist $^{124}$ applied demineralized bone matrix to the rat exoskeleton and found that it caused differentiation of cartilage and bone in 1965. After 19 years of laboratory work, he succeeded in isolated this substance and labeled it BMP. ${ }^{125}$ Since the initial discovery of BMP, 14 different types have been isolated and meticulously analyzed. ${ }^{21}$ In 2002, rhBMP-2 (INFUSE, Medtronic) was approved for anterior lumbar interbody fusion (ALIF) cage procedures; it is reported to result in fusion rates that are superior to those associated with autograft. ${ }^{17}$ In 2006, RhOP-1 (rhBMP-7, Stryker Corp.) was approved for fusion augmentation procedures in the lumbar spine. ${ }^{16}$ However, these products are very expensive, but when length of hospital stay, reoperation rates, and return to activities of daily living are factored in, some suggest a net savings. ${ }^{38,41}$ 


\section{J. H. Oppenheimer, I. DeCastro, and D. E. McDonnell}
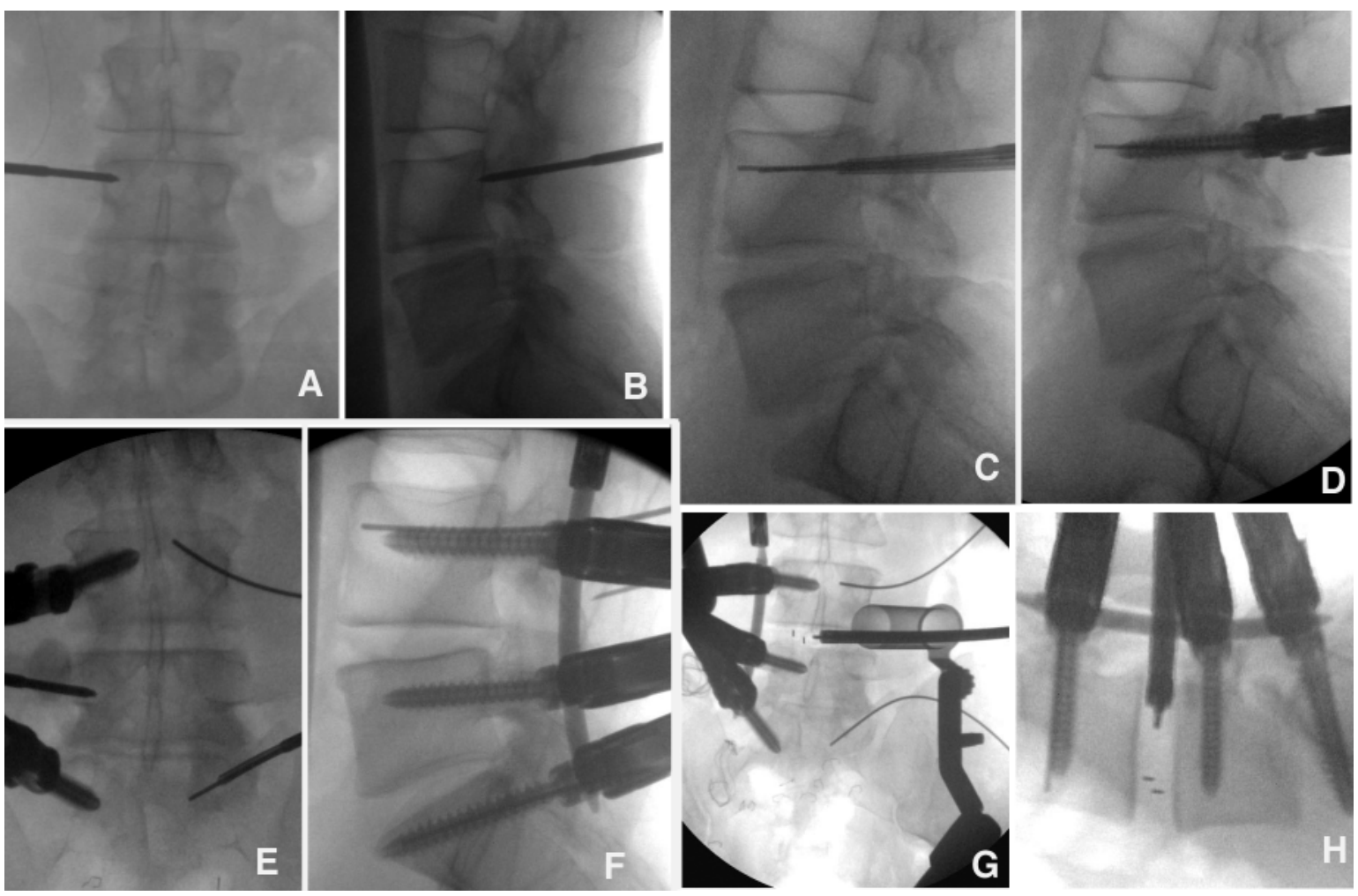

FIG. 6. Intraoperative fluoroscopic images demonstrating left MIS L3-4 and L5-S1 TLIF procedures with percutaneous screws and PEEK interbody spacers. The patient was a 35-year-old man with a history of multiple surgical procedures for L4-5 and L5-S1 disc disease. He required 1 day of patient-controlled analgesia use following surgery and his radiculopathy resolved. A and B: Jamshidi needle placement to junction of pedicle and posterior cortex of vertebral body. C: Soft-tissue dilation and guidewire placement. D: Cannulated screw placed over a guidewire. E: Right L-4 and S-1 screws in place and Jamshidi needle in L-5 along with contralateral wires. F: Percutaneous delivery of rod to screws through 3 pedicle screws on the right using arc system. G: Detachment of rod delivery device on left (left) and anterior view of PEEK interbody spacer (vertical dark lines) containing rhBMP-2 and local autograft being placed using MAST through a 22-mm METRX tube (right). Guidewires for pedicle screw are in place at L-4 and S-1, splayed divergently to accommodate tubular retractor. $\mathrm{H}$ : Lateral view of PEEK interbody spacer (horizontal dark lines) placement and titanium pedicle screws and rods in place.

The use of BMP, as an adjuvant to autograft or for primary use in arthrodesis, has been a major technical advance in the field of MAST in the lumbar spine as these substances are malleable and small in volume so they can be easily placed. ${ }^{4,15}$ Typically, $<1 \mathrm{ml}$ of the product is added to a collagen carrier or "sponge," which facilitates placement in small surgical corridors. Initially, few complications were reported. ${ }^{13,85}$ Anecdotes about the impressive effects of BMP products on bone formation spread through the spine surgery community and may have preceded much of the scientific reporting. Enthusiasm for the product manifested in significant off-label, non-FDA-approved use, and complications were reported. This was particularly true in the cervical spine, as data suggested that, not only does BMP cause ectopic bone formation in posterior fusion, but it can also cause postoperative swelling, dysphagia, and hematoma in anterior cervical discectomies. ${ }^{118}$ The use of BMP in MAST arthrodesis procedures should continue to be guided by evidencebased medical practice.

The development of spinal instrumentation is significant in the history of MAST. Pedicle fixation was originally described by Michele and Krueger in 1949. ${ }^{3}$ The first percutaneous screw placement technique was reported by Magerl in 1982 and involved the use of external fixators. ${ }^{78}$ The development of technology for MAST placement of rods and pedicle screws was driven by concerns over the amount of paraspinal muscle retraction required in the open approaches. Bilateral pedicles are typically accessed through a midline incision. The distance to the dorsal pedicle entry point or transverse process junction is far lateral and deep and may require significant paraspinal retraction, especially in muscular and stout individuals. In addition, screw placement is often performed at the end of a procedure after lengthy decompression, discectomy, and interbody implant placement, although some spine surgeons place screws first. In an effort to expose the lateral aspects of the spinal canal, retraction of the paraspinal muscles is often forceful. In addition, open lumbar fusions are typically lengthy procedures and require long periods of exposure. The result of these exposure techniques can be ischemic necrosis of the paraspinal muscles, and it is our opinion that this is one of the primary causes of the chronic back pain seen in postlaminectomy syndrome and "fusion disease." Efforts to limit this effect date back to Wiltse in 1988 with the development of the bilateral muscle splitting approaches to the dorsal lumbar spine. ${ }^{133}$ Foley made a significant 

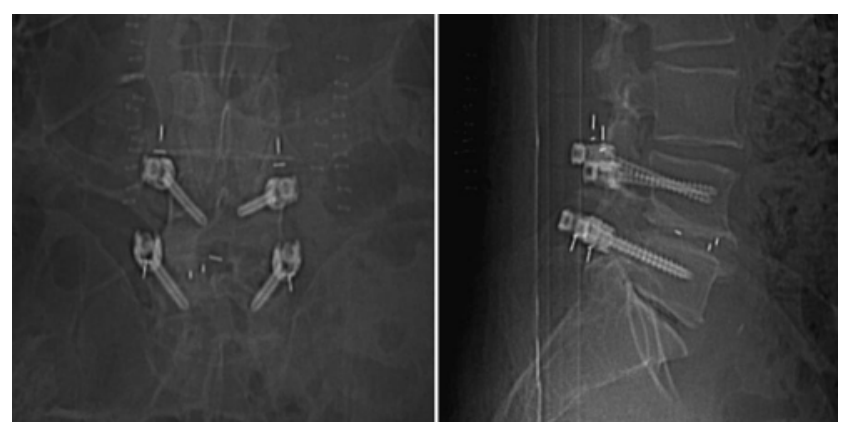

FIG. 7. Postoperative anteroposterior and lateral plain radiographs demonstrating PEEK rods (vertical white lines) and interbody spacers (short horizontal and vertical white lines). The patient was a 61-year-old man who underwent MIS dynamic stabilization for back pain and radiculopathy following previous decompressive laminectomy at $L 4-5$. The rods and interbody spacers were placed using MAST-MIS left L4-5 LIF performed using a 22-mm METRx tube and Sextant percutaneous pedicle screw and rod system.

contribution to resolving this dilemma in 2001 with his invention of instruments and a technique to pass rods in a minimally traumatic fashion using an arc-based system called Sextant (Medtronic). ${ }^{33}$ Other MIS pedicle screw systems followed, with the release of the Mantis system in 2007 (Stryker); this is a percutaneous system in which rod placement is accomplished by top loading but it is yet to be reported in the literature. Percutaneous pedicle access and rod placement can not only minimize the issue of muscle ischemia but can also facilitate medialization of the distal end of the screw (delta angle), thereby increasing pullout strength. Minimal access spinal technique also allows the surgeon to bury screw heads deep within the recess of the transverse process junction allowing for a lower rod profile. This can lessen the risk of disrupting the adjacent facet joints outside the intended segments of the construct.

The Sextant technique involves placing guidewires through the pedicles passing between 50 and $75 \%$ of the sagittal length of the vertebral body. Jamshidi needles coupled to intraoperative electromyographic monitoring can be used to increase safety, and biplanar imaging is essential. Standard tubular dilation techniques are performed over the wires. A cannulated tap is placed over them, screw holes are made, and the screws are placed. The screw towers are then coupled together and an arc device with a perforating tip at its distal end is connected to them. The tip is then rotated down to meet the skin. A distal stab incision is then made and the arc is pushed through to make a subcutaneous tract to the aperture of the most proximal screw. A measuring device is then placed on the arc system to calculate rod length. The arc is swung back and temporarily withdrawn, and the perforating tip is replaced with the premeasured rod. It is then passed through the previously made tract that is typically in an ideal vector to engage both screw apertures. Two-level fixation using 3 screws can be performed using similar techniques (Fig. 6); PEEK rods for dynamic fixation are also available and can be placed using MAST (Fig. 7).

Both percutaneous pedicle and facet screw procedures have served as adjuvants in the development of minimally

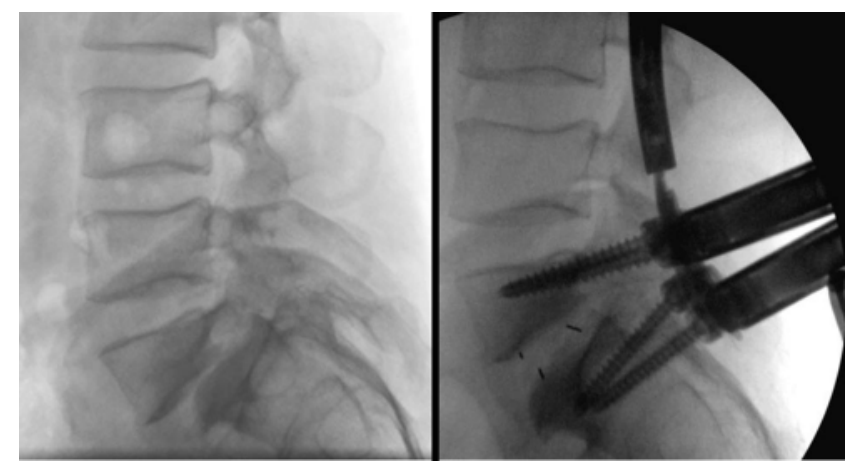

FIG. 8. Immediate preoperative (left) and postoperative (right) fluoroscopic images demonstrating anatomical reduction of a Grade II-III spondylolisthesis using percutaneous reduction screws in a 48-yearold patient with low-back pain and bilateral radiculopathy.

invasive interbody fusion and ADR techniques. The use of percutaneous facet fusion techniques was reported by Jang et al. in $2003 .{ }^{56}$ The chronology of open techniques for accessing the disc space includes development of the ALIF procedure by Burns in 1933, ${ }^{18}$ PLIF by Cloward in $1952,{ }^{25}$ ADR by Fernstrom in $1966,{ }^{35}$ and transforaminal interbody fusion (TLIF) by Harms and Rolinger in 1982. ${ }^{46}$ Adaptation of MAST to these technologies began when Obenchain published the first report of an anterior laparoscopic disc removal in 1991.93 In 1995, Matthews ${ }^{81}$ and Zucherman ${ }^{138}$ pioneered minimally invasive access that is used for both the ALIF and ADR techniques. Khoo reported the first MIS-PLIF procedures in 2002.62 In 2006, a paper by Holly and Schwender and colleagues described good results obtained by performing MISTLIFs using tubular retractors. ${ }^{49}$ Percutaneous reduction screws (CD Horizon Sextant, Medtronic, Inc.) were released in 2008, and Park and Foley used this technology along with PEEK interbody spacers to perform MISTLIF procedures in patients with Grades I and II isthmic spondylolisthesis. Their results demonstrated that good deformity correction could be achieved along with clinical outcomes that were comparable to those seen with the use the open techniques such as Gill laminectomy. ${ }^{98}$ This has also been the experience of the primary author (J.H.O.) at CAVHS (Fig. 8). Rosen and Fessler recently demonstrated that the use of MAST for posterior lumbar fusion may have significant advantages over traditional open procedures in the obese population. ${ }^{109}$

The far-lateral, extracavitary transpsoas approach is an effective surgical portal to gain access to the anterior lumbar spine to treat degenerative disc disease using intervertebral spacers and fusion techniques. The direct lateral transpsoas approaches to the lumbar disc space (DLIF, Medtronic, Inc.; XLIF, Nuvasive) were developed as MIS procedures from techniques reported by Mayer in $1997^{82}$ and refined by McAffee ${ }^{83}$ and Pimenta in 1998 (Pimenta L, presented at the VII Brazilian Spine Society Meeting, 2001). Dissection is straightforward through the anatomical fat plane of the retroperitoneum with minimal trauma. It is performed through a long tubular retractor that is guided by anteroposterior and lateral fluoroscopy. Prior to dissecting through the psoas muscle, accurate intraoperative neural monitoring is imperative to local- 

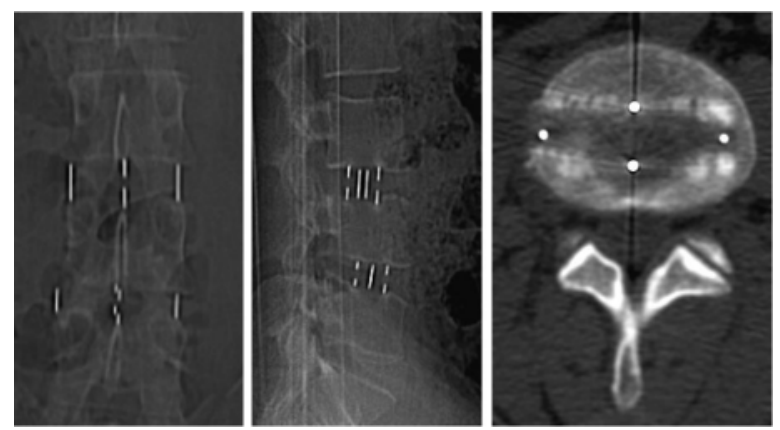

FIG. 9. Example of a PEEK spacer used in a DLIF procedure performed in 32-year-old man who had undergone previous discectomies at L3-4 and L4-5 and complained of leg and back pain. Left and Center: Plain radiographs demonstrating an intervertebral spacer containing rhBMP-2. Right: Axial CT scan showing the L3-4 intervertebral spacer.

ize the lumbosacral plexus safely. Small adjustments in the direction of the tube (wanding) can be made to avoid these structures based on electromyographic feedback. Nevertheless, a good understanding of the lumbosacral plexus and its varying, segment-dependent relationship to the lateral belly of the psoas and the surface of the vertebral column are essential. ${ }^{2} \mathrm{~A}$ recent report documents that complications are infrequent and consist mainly of transient leg weakness and dysthesthesiae. ${ }^{67}$ The PEEK spacers that have been developed for this procedure are wide and long and provide a large surface area for fusion, generous reconstruction of collapsed disc spaces, and ligamentotaxis for stenosis. These spacers can be used alone or may be supplemented by lateral plates or posterior screws-all of which can be placed using MAST. Our practice has been to achieve bicortical purchase giving the implants a tight fit and obviating the need for a secondary tension band (Fig. 9).

The transaxial approach or AxiaLIF (TranS1, Inc.), a procedure that utilizes MAST, was first reported in 2004 by Cragg. ${ }^{26}$ It is typically used for L5-S1 fusions, with the AxiaLIF implant being placed using a small perianal incision to expose and develop a surgical plane anterior to the sacrum and coccyx. An anatomical fat pad is located in this region that is typically avascular. This facilitates dissection and opens a wide corridor to the base of the sa- crum. Using this access, a large threaded rod is placed in a caudorostral direction down the central axis of the S-1 and L-5 vertebral bodies across the evacuated and decorticated disc space. Bone morphogenetic protein products, such as BMP-7 or rhBMP-2, or alternative allograft and/ or autograft can then be placed through the device via a tubular portal to obtain interbody fusion. The TranS1 rod can also achieve distraction of the disc space. Though this is unfamiliar anatomy to most spine surgeons, early experience suggests that the procedure has a quick learning curve. The AxiaLIF is not a stand-alone technique and is typically followed by minimally invasive bilateral facet or pedicle screw fixation (Fig. 10). The tension band is necessary to limit axial rotation, keep the implant in place, and enhance arthrodesis. This procedure might provide a "virgin" corridor for a previously operated segment if anterior access is contraindicated or might be used de novo. Another unique feature of this approach and device is that they enable the surgeon to fuse the transition segment L5-S1 without removing implants from more rostral, previously instrumented segments. This is an intriguing concept, but outcomes need to be studied. Recent FDA approval has been given for 2-level fusions, L-4 through S-1.

\section{Disorders of the Thoracic Spine}

The first surgical management of thoracic disc disease was reported by Benjamin in 1983. ${ }^{14}$ Thoracic discectomy was adapted to MAST by using the endoscopic technologies in a cadaver model, and this was reported by Horowitz in $1994 . .^{51}$ The first clinical reports were published by Rosenthal in $1994^{110}$ and later by Jho in $1999 . .^{58}$ These MIS techniques and technologies are far less morbid and can be adapted to many of the open procedures for thoracic disc access: thoracotomy, costotransversectomy, and the far-lateral extracavitary approach. Refinements of MIS thoracic discectomy technique using the tubular retractor were reported by Lidar and colleagues in $2005 .{ }^{77}$ Disc calcification and midline versus lateral location come into play when choosing a MAST thoracic procedure just as they do with the more traditional open approaches.

Minimal access spinal techniques have been adapted
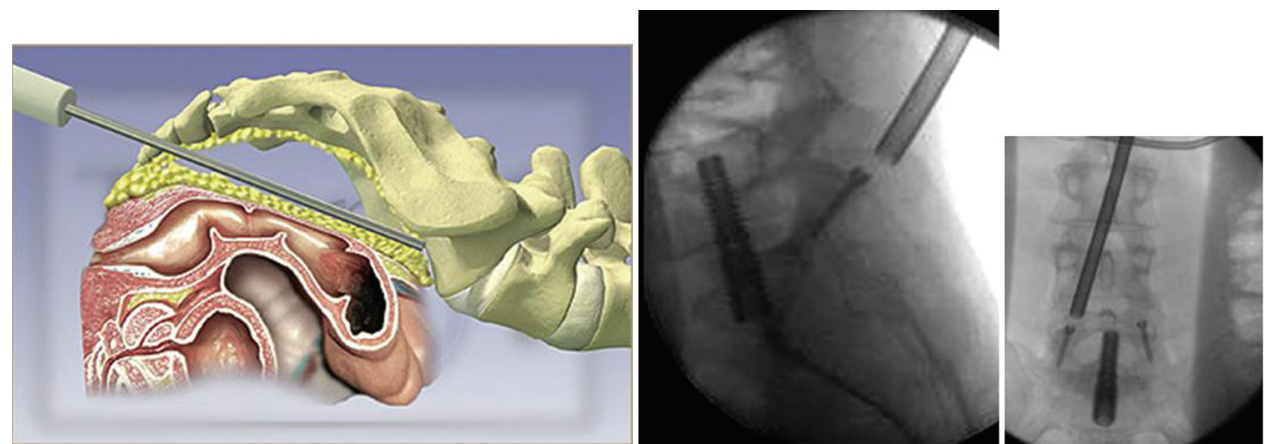

FIG. 10. AxiaLIF technique. Left: Illustration of lateral view of a probe spanning presacral space and fat pad. The instrument is touching the anterior sacrum at the promontory. Right: Intraoperative lateral and anteroposterior fluoroscopic images demonstrating minimally invasive placement of right L5-S1 facet screw through a tubular retractor. The AxiaLIF rod is in place along with the contralateral facet screw. Images used with permission from TranS1. 


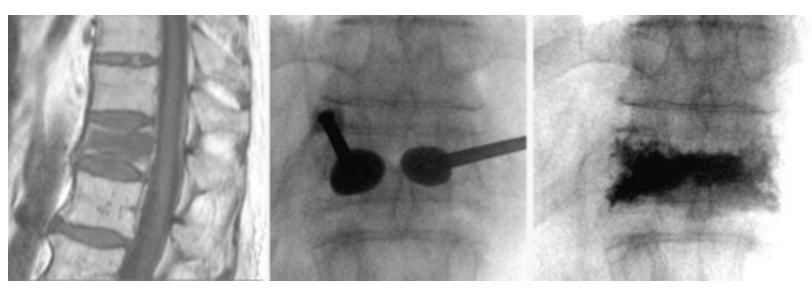

FIG. 11. Images of a kyphoplasty obtained in a 79-year-old man who presented with severe low-back pain 2 days after a fall. The patient underwent kyphoplasty the next day and was ambulating pain-free immediately after the procedure. Left: Preoperative sagittal T1-weighted MR image demonstrating T-12 compression fracture. Center and Right: Anteroposterior fluoroscopic images demonstrating balloon inflation causing end plate elevation and height restoration (center) and methylmethacrylate cement placed in void (right).

to the surgical management of osteoporotic compression fractures. Minimally invasive treatment is ideal for these lesions as they typically occur in elderly patients who are often medically debilitated. Prior to 1989, most of these patients were treated with bed rest and bracing as they could not tolerate the significant blood loss and anesthetic morbidity generally associated with large open spinal instrumentation procedures. However, these nonsurgical treatments made patients susceptible to skin breakdown and pulmonary emboli from deep vein thromboses associated with immobility. Management often required extended hospital stays with long periods of rehabilitation at great cost. Vertebroplasty, invented by Galibert in 1984, was considered the first MAST procedure for the treatment of these lesions, although it was initially used to manage vertebral angiomas. ${ }^{37}$ The first report of its use in the treatment of osteoporotic compression fractures was by Lapras and colleagues 5 years later. ${ }^{72}$ This is a needle technology that involves injecting bone cement under pressure to fill the osteoporotic bone cavity of a compression fracture. Reports have been promising, although opponents claim that the results are limited by lack of height restoration and inadequate correction of sagittal balance. $28,43,137$ The technique of inflatable balloon tamp placement was first reported by Wong and colleagues in 2000 and addresses these issues by restoring height. This is done by creating a void in the collapsed vertebra by using curettes and expandable balloons of different selected volumes. ${ }^{134}$ The cavity associated with the restored vertebral height is then typically filled with methylmethacrylate (Fig. 11). Both procedures can be performed under local anesthesia by either an interventional radiologist or a spine surgeon, and multiple segments can be treated in 1 sitting.

Minimally invasive thoracic pedicle screw placement for degenerative and traumatic lesions of the thoracic spine is one of the newest frontiers in MAST. Thoracic pedicles can be small, and surface landmarks can be challenging to identify even during open procedures. The morbidity associated with screw misplacement in the thoracic (as compared to lumbar) segments is much greater because of the greater potential for spinal cord injury, paraplegia, and great vessel injury leading to death. Open procedures using laminar and pedicle claw constructs have been used in the past to avoid these complications, but extrapedicular fixation tends to be suboptimal, particularly in the setting of severe instability. In addition, the ability of these latter constructs to achieve deformity correction can also be limited. Minimally invasive placement of thoracic pedicle screws has been developed using cannulated screws and the technique is performed using imaging guidance (for example, intraoperative fluoroscopy). The CD Horizon Longitude system (Medtronic, Inc.) was released in 2008 and may be used for fracture fixation, stabilization, and deformity correction. Once the reduction-type pedicle screws are placed, rods are placed by means of a hand-held device, similar to a technique described earlier in this report (Sextant). As reported by Anand et al. ${ }^{6}$ in 2008, MAST utilizing percutaneous pedicle screws has been found to produce favorable results in scoliosis correction. Percutaneous placement of cannulated pedicle screws has also been used effectively to treat Chance-type fractures. ${ }^{116}$ In addition, MIS decompressive laminectomies using tubular retractors, similar
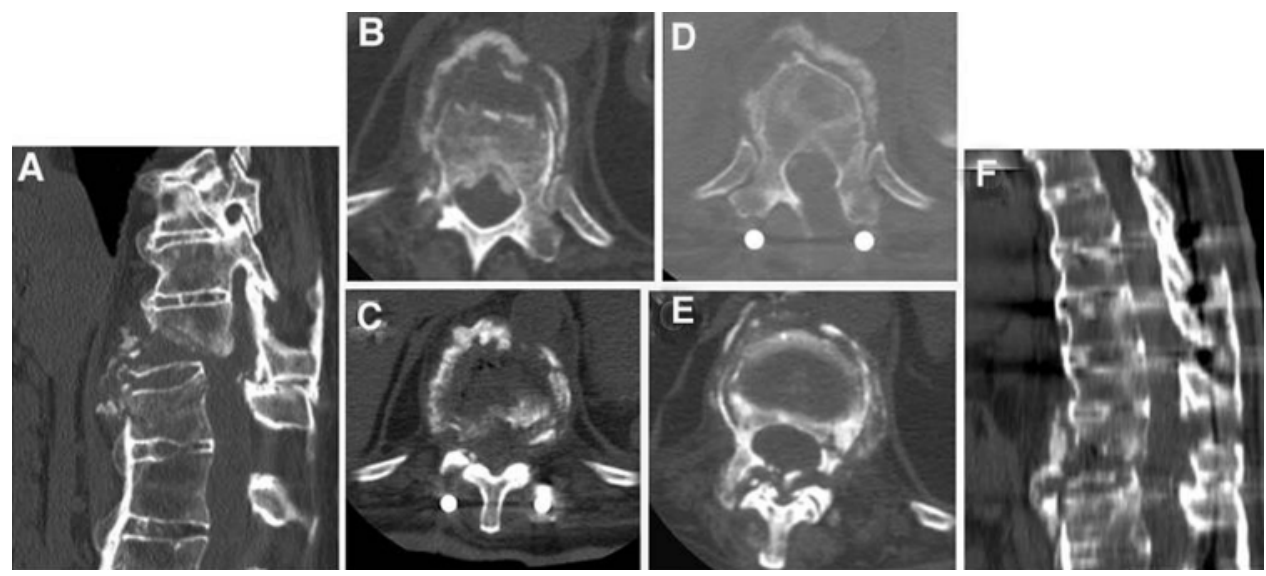

FIG. 12. Example of MIS fracture reduction results. A and F: Sagittal-reconstructed pre- and postoperative CT images obtained in a 66-year-old with a T-11 fracture-dislocation and an incomplete neurological injury. B-E: Pre- and postoperative axial CT images demonstrating fracture reduction. Restoration of sagittal balance is shown using percutaneous pedicle screws and ligamentotaxis. D: Axial CT image showing an MIS-decompression of T-11 that was performed from a left-sided approach using a 16-mm METRx tube. 
J. H. Oppenheimer, I. DeCastro, and D. E. McDonnell
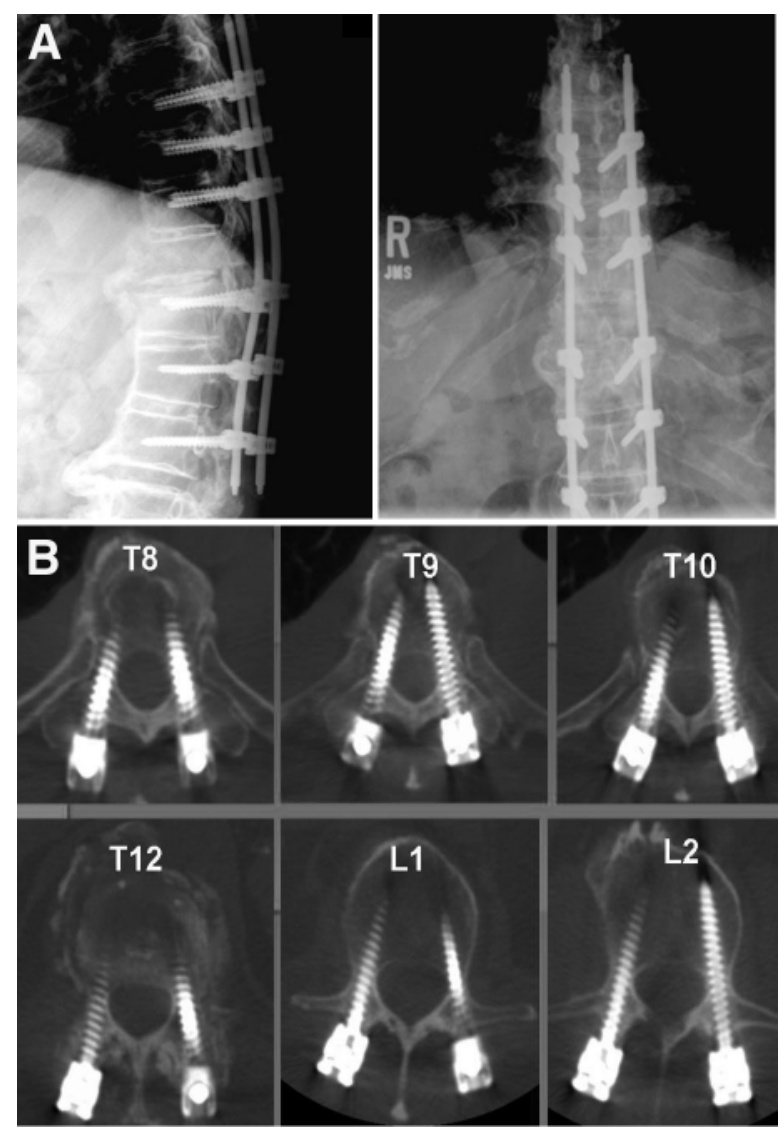

FIG. 13. Final construct from the case illustrated in Fig. 12. A: Postoperative anteroposterior (left) and lateral (right) plain radiographs. B: Postoperative axial CT images demonstrating pedicle screws placed using MAST (Longitude system).

to techniques described earlier in this report for lumbar stenosis, can serve as useful adjuvants to these posterior rod-screw constructs both to decompress the spinal canal and to correct deformity (Figs. 12 and 13).

\section{Disorders of the Cervical Spine}

Much of what we have learned about the classic open techniques for the treatment of cervical spine disease is based on the treatment of traumatic injuries during the Korean conflict. ${ }^{128}$ The field of MAST for cervical disease has progressed over the past decade in spite of greater relative risk in this region of the spine. Some of the earliest procedures consisted of MIS odontoid screw placement, which was first reported by Horgan et al. in 1999.50 One of the main controversies in the open, classical surgical treatment of degenerative disease of the cervical spine is whether to address spondylotic and disc pathologies from an anterior or posterior approach. Open laminoforaminotomy for cervical disc and spondylotic disease was pioneered by Elsberg in $1925 .{ }^{29}$ This procedure allows the surgeon to effectively address lateral herniations and/ or osteophytes with preservation of disc space and motion. ${ }^{9,19,32,55}$ However, many feel that this management is ineffective for neck pain. Anterior cervical discectomy and fusion (ACDF) was first reported by Robinson and Smith

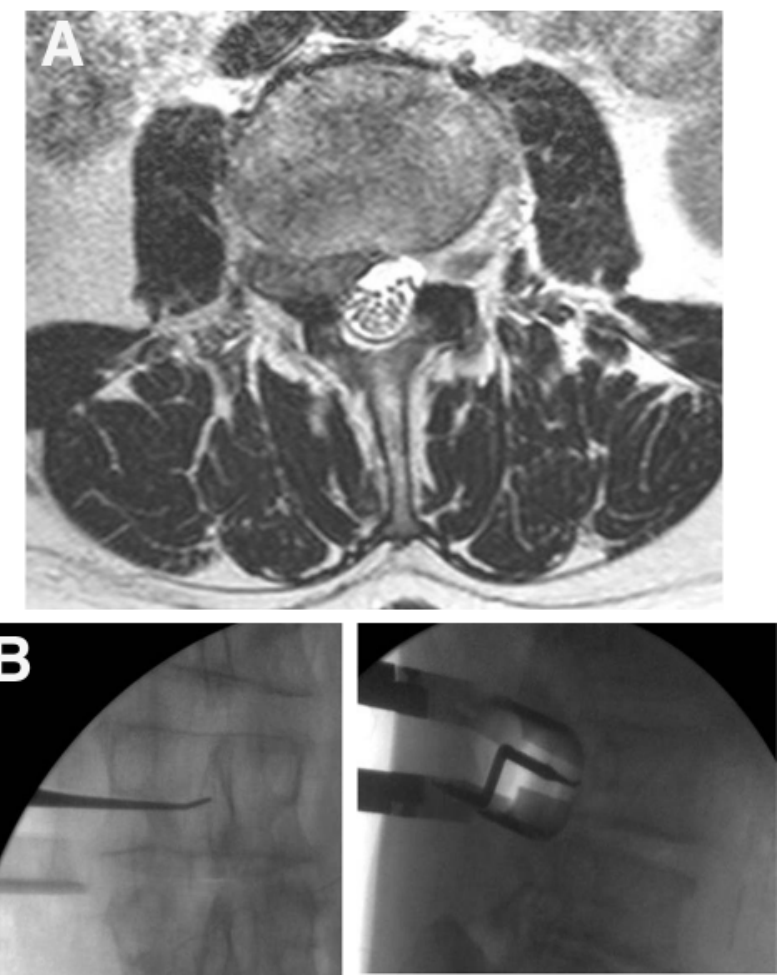

FIG. 14. Transpsoas access (normally used for DLIF and XLIF) for removal of lateral disc herniation. A: Preoperative MR image obtained in a 68-year-old man who underwent removal of foraminal and far-lateral disc herniation and a reactive neuroma. B: Intraoperative fluoroscopic image showing tubular retractor in position with instrument in the $\mathrm{L}-3$ foramen under the pedicle.

in $1955^{107}$ and modified by Cloward in $1958 .{ }^{24}$ Laminoforaminotomy was first adapted to MAST by Roh using tubular retractors and endoscopy in cadavers in $2000^{108}$ and then in the clinical setting by Adamson in 2001. ${ }^{1}$ Epstein suggests that there is negative risk-benefit ratio in the use of MIS cervical foraminotomies and favors the use of open techniques, ${ }^{30}$ but it is our opinion that complications are avoided by eliminating use of guidewires to begin the process of soft tissue dilation. In 2008, MIS-ACDF using endoscopic techniques was reported by Ruetten et al. ${ }^{111}$ In the same year, anterior cervical nucleoplasty using percutaneous techniques in cadavers was described by Li et al. ${ }^{76}$ The use of MAST for cervical instrumentation has been described. Wang and colleagues ${ }^{130}$ were the first to report on its clinical use in the placement of lateral mass screws. Open cervical laminoplasty was developed as a treatment for myelopathy by Tsuji in $1982,{ }^{123}$ and minimally invasive techniques for this procedure were developed in cadavers by Wang in $2003^{129}$ and by Perez-Cruet in the clinical setting in $2004 .{ }^{101}$

\section{Miscellaneous Applications}

Innovative use of MAST continues to be reported in the literature. The minimally invasive retroperitoneal transpsoas approach has been described as an excellent artificial disc retrieval procedure. Many of the complica- 
tions associated with repeat anterior access surgery, including catastrophic great vessel injuries, can be avoided in this manner as this corridor can provide a surgical plane free of adhesions. ${ }^{102}$ In a recent case report, Leng et al. ${ }^{75}$ describe resection of an os odontoideum through an endonasal technique. Vasudevan et al. ${ }^{126}$ reported treatment of a gunshot wound to the spine using a METRx tube. Transoral vertebroplasty has been used to treat a high cervical compressive fracture, as reported by Tong and colleagues. ${ }^{122}$ Lumbar synovial cyst rupture can be effectively treated by both tubular access ${ }^{113}$ and percutaneous needle aspiration. ${ }^{5}$

As discussed earlier, unintended durotomy can be a complication associated with early experience with tubular retractor use. Chou et al. ${ }^{23}$ reported a technique for repairing a lumbar CSF leak after a MAST procedure using a knot-tying instrument outside the retractor. It has been our observation that the natural history of CSF leak and/ or pseudomeningocele formation associated with MAST procedures differs from that of these conditions when they occur in the open setting. Early in our experience, punctate or linear dural tears were successfully managed with patches and fibrin glue and did not require an overnight hospital stay or bed rest. Our hypothesis is that the dilatation techniques and METRx access limit the amount of dead space created and maintain the structural integrity of the surgical corridor. The muscles can involute once retractors are withdrawn and this provides effective tamponade for any on-lay durotomy repair products.

\section{Discussion}

Since 1969, and especially in the past 2 decades, there has been a profound evolution in efforts to treat disorders of the spine using minimal access. Much of this has been fueled by technological advances in microscopy, diagnostic imaging, intraoperative neural monitoring, intraoperative fluoroscopy/CT, and minimally invasive spinal instrumentation technologies. The results of these efforts have reduced health care costs by limiting morbidity and shortening hospital stays. Minimally invasive procedures and technologies can be broadly characterized as traditional open procedures through small incisions (open microdiscectomy), fine needle procedures (chemonucleolysis, nucleotome procedures, vertebroplasty, and kyphoplasty), endoscopy (thorascopic discectomy, deformity management, and trauma management), tubular retractor-muscle dilation (MED, METRx, XLIF, DLIF, Sextant, Mantis, and Longitude), and miscellaneous technologies (laser-assisted percutaneous discectomy, APLD, X-STOP, and AxiaLIF).

Minimal access spine techniques hold promise for an exciting future. The impact of image guidance on the acceptance and use of MAST is uncertain. It is our opinion that most of these systems require cumbersome registration and may have steep learning curves that initially lengthen operating times significantly. However, this may change with continued utilization of 3D imaging technologies such as the Iso-C3D and $\mathrm{O}$ arm. Examples of current work in MAST clinical research include reports on hybrid procedures such as open kyphoplasty with Sex- tant screws. ${ }^{36}$ In addition, studies are now being carried out in both patients and animals using tubular retractors to perform minimally invasive thoracic corpectomies and reconstruct the vertebra with expandable cages. ${ }^{64}$ These procedures can be performed in the clinical setting for the treatment of both cancer and trauma. At CAVHS, we are adapting the MIS extracavitary transpsoas approach that was initially developed for interbody fusion (DLIF, XLIF) as a treatment for far-lateral and foraminal disc herniations above the L5-S1 level (Fig. 14). These approaches along with many of our other uses of MAST are creating an environment in which more and more of the individuals who undergo elective spine procedures at our institution are outpatients or have only overnight hospital stays - something not seen frequently in the veteran population. Education in MAST has become extremely popular and is currently available in the form of both Continuing Medical Education training and fellowship programs. In our sister institution, the University of Arkansas for Medical Sciences, we have now made training in MAST procedures a regular component of the neurosurgery rotation at CAVHS. Residents are routinely taught to perform complete or limited discectomy through a 7-mm incision and 14-mm METRx tube. We hope that more neurosurgical residencies will follow and offer training in these techniques.

There is a need for continued study of MAST and its associated technologies. The impact of limited soft-tissue disruption achieved by these procedures may reduce or perhaps eliminate the development of adjacent segment disease. The authors anticipate that these technologies will play an important role in ongoing technological efforts to preserve motion in the spine. This will most likely include nuclear replacement substances that are introduced into the annulus. ${ }^{65,104}$ Facet arthroplasty techniques are currently being developed ${ }^{117}$ and appear much more amenable to MAST than ADR procedures. With these advancements, the postlaminectomy and failed back syndromes may be significantly reduced. Over time, MAST technology training will become established in the curriculum of spinal surgery. Continued improvements in surgical outcomes will occur with greater use and refinements in these technologies and better training in these procedures.

\section{Disclaimer}

The authors report no conflict of interest concerning the materials or methods used in this study or the findings specified in this paper.

\section{References}

1. Adamson TE: Microendoscopic posterior cervical laminoforaminotomy for unilateral radiculopathy: results of a new technique in 100 cases. J Neurosurg 95 (1 Suppl):51-57, 2001

2. Albee FH: Transplantation of a portion of the tibia into the spine for Pott's disease. A preliminary report. JAMA 57:885886,1911

3. Albert TJ, Jones AM, Balderston RA: Spinal instrumentation, in Rothman RH, Simeone FA (eds): The Spine, ed 3. Philadelphia: WB Saunders, 1992, Vol 2, pp 1777-1796 


\section{J. H. Oppenheimer, I. DeCastro, and D. E. McDonnell}

4. Alden TD, Pittman D, Beres EJ, Hankins GR, Kallmes DF, Wisotsky BM, et al: Percutaneous spinal fusion using bone morphogenetic protein-2 gene therapy. J Neurosurg 90 (1 Suppl):109-114, 1999

5. Allen TL, Tatli Y, Lutz GE: Fluoroscopic percutaneous lumbar zygapophyseal joint cyst rupture: a clinical outcome study. Spine J 9:387-395, 2009

6. Anand N, Baron EM, Thaiyananthan G, Khalsa K, Goldstein TB: Minimally invasive multilevel percutaneous correction and fusion for adult lumbar degenerative scoliosis. J Spinal Disord Tech 21:459-467, 2008

7. Ascher PW, Heppner F: CO2-laser in neurosurgery. Neurosurg Rev 7:123-133, 1984

8. Austin RT, Zuk JA: Epidural adhesions after chymopapain chemonucleolysis. J R Coll Surg Edinb 34:30-32, 1989

9. Bapat MR, Chaudhary K, Sharma A, Laheri V: Surgical approach to cervical spondylotic myelopathy on the basis of radiological patterns of compression: prospective analysis of 129 cases. Eur Spine J 17:1651-1663, 2008

10. Barth M, Weiss C, Theme C: Two-year outcome after lumbar microdiscectomy versus microscopic sequestrectomy: part 1: evaluation of clinical outcome. Spine 33:265-272, 2008

11. Barth M, Deipers M, Weiss C, Thome C: Two year outcome after lumbar microdiscectomy versus microscopic sequestrectomy: part 2: radiographic evaluation and correlation with clinical outcome. Spine 33:273-279, 2008

12. Benglis DM, Vanni S, Levi AD: An anatomical study of the lumbosaccral plexus as related to the minimally invasive transpsoas approach to the lumbar spine. J Neurosurg Spine 10:139-144, 2009

13. Benglis D, Wang MY, Levi AD: A comprehensive review of the safety profile of bone morphogenetic protein in spine surgery. Neurosurg 62 (2 Suppl):ONS423-ONS431, 2008

14. Benjamin V: Diagnosis and management of thoracic disc disease. Clin Neurosurg 30:577-605, 1983

15. Boden SD, Martin GJ Jr, Horton WC, Truss TL, Sandhu HS: Laparoscopic spinal arthrodesis with rhBMP-2 in titanium interbody threaded cage. J Spinal Disord 11:95-101, 1998

16. Brown A, Stock G, Patel AA, Okafor C, Vaccaro A: Osteogenic protein-1: a review of it utility in spinal applications. BioDrugs 20:243-251, 2006

17. Burkus JK, Heim SE, Gornet MF, Zdeblick TA: Is INFUSE bone graft superior to autograft bone? An integrated analysis of clinical trials using the LT-CAGE lumbar tapered fusion device. J Spinal Disord Tech 16:113-122, 2003

18. Burns BH: An operation for spondylolisthesis. Lancet 1:1233, 1933

19. Caglar YS, Bozkurt M, Kahilogullari G, Tuna H, Baker A, Torun F, et al: Keyhole approach for posterior cervical discectomy: experience in 84 patients. Minim Invasive Neurosurg 50:7-11, 2007

20. Carragee EJ, Spinnickie AO, Alamin TF, Paragioudakis S: A prospective controlled study of limited versus subtotal posterior discectomy: short term outcomes in patients with herniated lumbar intervertebral discs and large posterior annular defect. Spine 31:653-657, 2006

21. Cheng H, Jiang W, Phillips FM, Haydon RC, Peng Y, Zhou $\mathrm{L}$, et al: Osteogenic activity of the fourteen types of human morphogenetic proteins (BMPs). J Bone Joint Surg Am 85: 1544-1552, 2003

22. Chiu JC: Interspinous process decompression (IPD) system (X-STOP) for the treatment of lumbar spinal stenosis. Surg Technol Int 15:265-275, 2006

23. Chou D, Wang VY, Khan AS: Primary dural repair during minimally invasive microdiscectomy using standard operating room instruments. Neurosurgery 64 (2 Suppl):356-359, 2009

24. Cloward RB: The anterior approach for removal of ruptured cervical discs. J Neurosurg 15:602-617, 1958
25. Cloward RB: The treatment of ruptured lumbar intervertebral disc by vertebral body fusion. III. Methods and use of banked bone. Ann Surg 136:987-992, 1952

26. Cragg A, Carl A, Casteneda F, Dickman C, Guterman L, Oliveira C: New percutaneous access method for minimally invasive anterior lumbosaccral surgery. J Spinal Disord Tech 17:21-28, 2004

27. Dohrmann GJ, Rubin JM: Intraoperative ultrasound imaging of the spinal cord: syringomyelia, cysts, and tumors - a preliminary report. Surg Neurol 18:395-399, 1982

28. De Negri P, Tirri T, Paternoster G, Modano P: Treatment of osteoporotic or traumatic vertebral compression fractures by percutaneous vertebral augmentation procedures: a nonrandomized comparison between vertebroplasty and kyphoplasty. Clin J Pain 23:425-430, 2007

29. Elsberg CA: Tumors of the Spinal Cord and the Symptoms of Irritation and Compression of the Spinal Cord and Nerve Roots: Pathology, Symptomatology, Diagnosis, and Treatment. New York: Paul B Hoeber, 1925, pp 195-198

30. Epstein NE: Minimally invasive/endoscopic vs "open" posterior cervical laminoforaminotomy: do the risks outweigh the benefits? Surg Neurol 71:330-331, 2009

31. Faubert C, Caspar W: Lumbar percutaneous discectomy. Initial experience in 28 cases. Neuroradiology 33:407-410, 1991

32. Fehlings MG, Gray RJ: Posterior cervical foraminotomy for the treatment of cervical radiculopathy. J Neurosurg Spine 10:343-346, 2009

33. Foley KT, Gupta SK, Justis JR, Sherman MC: Percutaneous pedicle screw fixation of the lumbar spine. Neurosurg Focus 10(4):E10, 2001

34. Foley KT, Smith MM: Microendoscopic discectomy. Tech Neurosurg 3:301-307, 1997

35. Fernstrom U: Arthroplasty with intercorporal endoprosthesis in herniated disc and painful disc. Acta Chir Scand Suppl 357:154-159, 1966

36. Fuentes S, Blondel B, Metellus P, Adetchessi T, Gaudart J, Dufour $\mathrm{H}$ : Open kyphoplasty for management of severe osteoporotic spinal fractures. Neurosurgery 64 (2 Suppl):350-355, 2009

37. Galibert P, Deramond H, Rosat P, Le Gars D: [Preliminary note on the treatment of vertebral angioma by percutaneous acrylic vertebroplasty.] Neurochirurgie 233:166-168, 1987 (Fr)

38. Garrison KR, Donnell S, Ryder J, Shemilt I, Mugford M, Harvey I, et al: Clinical effectiveness and cost-effectiveness of bone morphogenetic proteins in the non-healing of fractures and spinal fusion: a systematic review. Health Technol Assess 11:1-150, 2007

39. German JW, Adamo MA, Hoppenot RG, Blossom JH, Nagle HA: Perioperative results following lumbar discectomy: comparison of minimally invasive discectomy and standard microdiscectomy. Neurosurg Focus 25(2):E20, 2008

40. Glasser O: Dr. W. C. Roentgen, ed 2. Springfield, IL: Charles C. Thomas, 1958

41. Glassman SD, Carreon LY, Campbell MJ, Johnson JR, Puno RM, Djurasovic M, et al: The perioperative cost of Infuse bone graft in posterolateral spine fusion. Spine J 8:443-448, 2008

42. Greiner-Perth R, Bohm H, Allam Y: A new technique for the treatment of lumbar far lateral disc herniation: technical note and preliminary results. Eur Spine J 12:320-324, 2003

43. Grohs JG, Matzner M, Trieb K, Krepler P: Minimal invasive stabilization of osteoporotic vertebral fractures. A prospective nonrandomized comparison of vertebroplasty and balloon kyphoplasty. J Spinal Disord Tech 18:238-242, 2005

44. Guiot BH, Khoo LT, Fessler RG: A minimally invasive technique for decompression of the lumbar spine. Spine 27:432438,2002 
45. Hadra BE: Wiring the spinous process in Pott's disease. Trans Am Orthop Assoc 4:206-208, 1891

46. Harms J, Rolinger H: [A one-stage procedure in operative treatment of spondylolisthesis: dorsal traction-reposition and anterior fusion.] Z Orthop Ihre Grenzgeb 120:343-347, 1982

47. Hibbs RA: An operation for progressive spinal deformities. NY Med J 93:1013-1016, 1911

48. Hijikata S: Percutaneous nucleotomy. A new concept technique and 12 years' experience. Clin Orthop 238:9-23, 1989

49. Holly LT, Schwender JD, Rouben DP, Foley KT: Minimally invasive transforaminal interbody fusion: indications, technique, and complications. Neurosurg Focus 20(3):E6, 2006

50. Horgan MA, Hsu FP, Frank EH: A novel endoscopic approach for anterior odontoid fixation: technical note. Minim Invasive Neurosurg 42:142-145, 1999

51. Horowitz MB, Moossy JJ, Julinan T, Ferson PF, Huneke K: Thoracic discectomy using video assisted thoracoscopy. Spine 19:1082-1086, 1994

52. Hott JS, Deshmukh VR, Klopfenstein JD, Sonntag VK, Dickman CA, Spetzler RF, et al: Intraoperative Iso-C C-arm navigation in craniospinal surgery: the first 60 cases. Neurosurgery 54:1131-1136, 2004

53. Hounsfield GN: Historical notes on computerized axial tomography. J Can Assoc Radiol 27:135-142, 1976

54. Hsu KY, Zuchermann JF, Hartjen CA, Mehalic TF, Implicito DA, Martin MJ, et al: Quality of life of lumbar stenosis-treated patients in whom the X STOP interspinous device was implanted. J Neurosurg Spine 5:500-507, 2006

55. Jagannathan J, Sherman JH, Szabo T, Shaffrey CI, Jane JA: The posterior cervical foraminotomy in the treatment of cervical disc/osteophyte disease: a single surgeon experience with a minimum of 5 years' clinical and radiographic followup. J Neurosurg Spine 10:347-356, 2009

56. Jang JS, Lee SH, Lim SR: Guide device for percutaneous placement of translaminar facet screws after anterior lumbar interbody fusion. Technical note. J Neurosurg 98:100-103, 2003

57. Jansen EF, Balls AK: Chymopapain: a new crystalline proteinase from papaya latex. J Biol Chem 137:459-460, 1941 (Letter)

58. Jho HD: Endoscopic transpedicular thoracic discectomy. J Neurosurg 91 (2 Suppl):151-156, 1999

59. Kambin P, Brager M: Percutaneous posterolateral discectomy: anatomy and mechanism. Clin Orthop Relat Res 223:145154,1987

60. Katayama Y, Matsuyama Y, Yoshishara H, Sakai Y, Nakamura $\mathrm{H}$, Nakashima $\mathrm{S}$, et al: Comparison of surgical outcomes between macro discectomy and micro discectomy for lumbar disc herniation: a prospective randomized study with surgery performed by the same spine surgeon. J Spinal Disord Tech 19:344-347, 2006

61. Kevles BH: Naked to the Bone: Medical Imaging in the Twentieth Century. Reading, MA: Addison-Wesley, 1997

62. Khoo LT: Minimally invasive percutaneous posterior interbody fusion. Neurosurgery 41:S2, 2002

63. Khoo LT, Fessler RG: Microendoscopic decompressive laminotomy for the treatment of lumbar stenosis. Neurosurgery 51 (5 Suppl):S146-S154, 2002

64. Kim DH, O’Toole, JE, Ogden AT, Eichholz KM, Song J, Christie SD, et al: Minimally invasive posterolateral thoracic corpectomy: cadaveric feasibility study and report of four clinical cases. Neurosurgery 64:746-753, 2009

65. Klara PM, Ray CD: Artificial nucleus replacement: clinical experience. Spine 27:1374-1377, 2002

66. Kleinberg S: The operative treatment of scoliosis. Arch Surg 5:631-645, 1922

67. Knight RQ, Schwaegler P, Hanscom D, Roh J: Direct lateral lumbar interbody fusion for degenerative conditions: early complication profile. J Spinal Disord Tech 22:34-37, 2009

68. Kocher T: Die Verletzungen der Wirbelsäule zugleich als Beitrag zur Physiologie des menschlichen Rückenmarks. Mitt Grenzgeb Med Chir 1:415-480, 1896

69. Kondrashov DG, Hannibal M, Hsu KY, Zucherman JF: Interspinous process decompression with the X-STOP device for lumbar spinal stenosis. A 4-year follow-up study. J Spinal Disord Tech 19:323-327, 2006

70. Kuchta J, Sobottke R, Eysel P, Simons P: Two year results of interspinous spacer (X-Stop) implantation in 175 patients with neurologic intermittent claudication due to lumbar spinal stenosis. Eur Spine J 18:823-829, 2009

71. Lane WA: Case of spondylolisthesis associated with progressive paraplegia: laminectomy. Lancet 1:991, 1893

72. Lapras C, Mottolese C, Deruty R, Lapras C Jr, Remond J, Duquesnel J: [Percutaneous injection of methyl-methacrylate in osteoporosis and severe vertebral osteolysis (Galibert's technique).] Ann Chir 43:371-376, 1989

73. Lauryssen C: Appropriate selection of patients with lumbar spinal stenosis for interspinous decompression with the XSTOP device. Neurosurg Focus 22(1):E5, 2007

74. Legorreta AP, Silber JH, Costantino GN, Kobylinski RW, Zatz SL: Increased cholecystectomy rate after the introduction of laparoscopic cholecystectomy. JAMA 270:1429-1432, 1993

75. Leng LZ, Anand VK, Hartl R, Schwartz TH: Endonasal endoscopic resection of os odontoideum to decompress the cervicomedullary junction: a minimal access surgical technique. Spine 34:E139-E143, 2009

76. Li J, Yan DL, Zhang ZH: Percutaneous cervical nucleoplasty in the treatment of cervical disc herniation. Eur Spine J 17:1664-1669, 2008

77. Lidar Z, Lifshutz J, Bhattacharjee S, Kurpad SN, Maiman DJ: Minimally invasive, extracavitary approach for thoracic disc herniation: technical report and preliminary results. Spine J 6:157-163, 2006

78. Magerl F: External skeletal fixation of the lower thoracic and lumbar spine, in Uhthoff HK, Stahl E (eds): Current Concepts of External Fixation of Fractures. New York: Springer-Verlag, 1982, pp 353-366

79. Maroon JC: Current concepts in minimally invasive discectomy. Neurosurgery 51 (5 Suppl):S137-S145, 2002

80. Maroon JC, Onik G: Percutaneous automated discectomy: a new method for lumbar disc removal. Technical note. J Neurosurg 66:143-146, 1987

81. Mathews HH, Evans MT, Molligan HJ, Long BH: Laparoscopic discectomy with anterior lumbar interbody fusion: a preliminary review. Spine 20:1797-1802, 1995

82. Mayer HM: A new technique of minimally invasive anterior lumbar spine fusion. Spine 22:691-699, 1997

83. McAfee PC, Regan JJ, Geis WP, Fedder IL: Minimally invasive anterior retroperitoneal approach to the lumbar spine. Emphasis on the lateral BAK. Spine 23:1476-1484, 1998

84. McKay WF, Peckham SM, Badura JM: A comprehensive clinical review of recombinant human bone morphogenetic protein-2 (INFUSE Bone Graft). Int Orthop 31:729-734, 2007

85. McKay B, Sandhu HS: Use of recombinant human bone morphogenetic protein-2 in spinal fusion applications. Spine (Phila Pa 1976) 27 (1 Suppl):S66-S85, 2002

86. McGirt MJ, Ambrossi GL, Datoo G, Sciubba DM, Witham TF, Wolinsky JP, et al: Recurrent disc herniation and longterm back pain after primary lumbar discectomy: review of outcomes reported for limited versus aggressive disc removal. Neurosurgery 64:338-344, 2009

87. McLoughlin GS, Fourney DR: The learning curve of minimallyinvasive lumbar discectomy. Can J Neurol Sci 35:75-78, 2008

88. Mixter WJ, Barr JS: Rupture of the intervertebral disc with involvement of the spinal canal. N Engl J Med 211:210-215, 1934 
89. Moon MS, Kim I, Ok IY, Lee KW: The response of nerve tissue to chymopapain. Int Orthop 14:79-83, 1990

90. Nenner RP, Imperato PJ, Rosenberg E: Increased cholecystectomy rates among Medicare patients after the introduction of laparoscopic cholecystectomy. J Community Health 19:409-415, 1994

91. Nolte LP, Zamorano LJ, Jiang Z, Wang Q, Langlotz F, Berlemann U: Image-guided insertion of transpedicular screws. A laboratory set-up. Spine 20:497-500, 1995

92. Nowitzke AM: Assessment of the learning curve for lumbar microendoscopic discectomy. Neurosurgery 56:755-762, 2005

93. Obenchain TG: Laparoscopic lumbar discectomy: case report. J Laparoendosc Surg 1:145-149, 1991

94. Obenchain TG: Speculum lumbar extraforaminal microdiscectomy. Spine J 1:415-420, 2001

95. Onik G, Helms CA, Ginsberg L: Percutaneous lumbar discectomy using a new aspiration probe: porcine and cadaver model. Radiology 155:251-252, 1985

96. Oppenheim H, Krause F: Über Einklemmung bzw. Strangulation der cauda equina. Dtsch Med Wochenschr 35:697-700, 1909

97. Palmer S, Turner R, Palmer R: Bilateral decompression of lumbar spinal stenosis involving a unilateral approach with the microscope and tubular retractor system. J Neurosurg 97 (2 Spine Suppl):213-217, 2002

98. Park P, Foley KT: Minimally invasive transforaminal interbody fusion with reduction of spondylolisthesis: technique and outcomes after a minimum of 2 years' follow-up. Neurosurg Focus 25(2):E16, 2008

99. Patwardhan RV, Hadley MN: History of surgery for ruptured disc. Neurosurg Clin N Am 12:173-179, 2001

100. Perez-Cruet MJ, Foley KT, Isaacs RE, Rice-Wyllie L, Wellington R, Smith MM, et al: Microendoscopic lumbar discectomy: technical note. Neurosurgery 51 (5 Suppl):S129-S136, 2002

101. Perez-Cruet MJ, Wang MY, Samartzis D: Microendoscopic cervical laminoplasty and laminectomy, in Kim DH, Fessler RG, Egan JJ (eds): Endoscopic Spine Surgery and Instrumentation. New York: Thieme, 2004, pp 74-87

102. Pimenta L, Diaz RC, Guerrero LG: Charité artificial disc retrieval: use of a lateral minimally invasive technique. Technical note. J Neurosurg Spine 5:556-561, 2006

103. Pollack IF, Welch W, Jacobs GB, Janecka IP: Frameless stereotactic guidance. An intraoperative adjunct in the transoral approach for ventral cervicomedullary junction decompression. Spine 20:216-220, 1995

104. Ray CD: The PDN prosthetic disc-nucleus device. Eur Spine J 11 (2 Suppl):S137-S142, 2002

105. Richards JC, Majumdar S, Lindsey DP, Beaupre GS, Yerby SA: The treatment mechanism of an interspinous process implant for lumbar neurogenic claudication. Spine 30:744-749, 2005

106. Robinson JS: Sciatica and the lumbar disc syndrome: a historical perspective. South Med J 76:232-238, 1983

107. Robinson RA, Smith GW: Anterolateral cervical disc removal and interbody fusion for cervical disc syndrome. Bull Johns Hopkins Hosp 96:233, 1955

108. Roh SW, Kim DH, Cardos AC, Fessler RG: Endoscopic foraminotomy using MED system cadaveric specimens. Spine 25:260-264, 2000

109. Rosen DS, Ferguson SD, Ogden AT, Huo D, Fessler RG: Obesity and self-reported outcome after minimally invasive lumbar spinal fusion surgery. Neurosurgery 63:956-960, 2008

110. Rosenthal D, Rosenthal R, de Simone A: Removal of a protruding thoracic disc using microsurgical endoscopy. A new technique. Spine 19:1087-1091, 1994

111. Ruetten S, Komp M, Merk H, Godolias G: Full-endoscopic anterior decompression versus conventional anterior decompression and fusion in cervical disc herniations. Int Orthop [epub ahead of print], 2008

112. Ryang YM, Oertel MF, Mayfrank L, Gilsbach JM, Rohde V:
Standard open microdiscectomy versus minimal access trocar microdiscectomy: result of a prospective randomized study. Neurosurgery 62:174-181, 2008

113. Sandhu FA, Santiago P, Fessler RG, Palmer S: Minimally invasive surgical treatment of lumbar synovial cysts. Neurosurgery 54:107-111, 2004

114. Saal JA, Saal JS: Intradiscal electrothermal treatment for chronic discogenic low back pain. Spine 25:2622-2627, 2000

115. Saal JS, Saal JA: Management of chronic discogenic low back pain with a thermal intradiscal catheter. A preliminary report. Spine (Phila Pa 1976) 25:382-388, 2000

116. Schizas C, Kosmopoulos V: Percutaneous surgical treatment of Chance fractures using cannulated pedicle screws. Report of two cases. J Neurosurg Spine 7:71-74, 2007

117. Serhan HA, Varnavas G, Dooris AP,Patwadhan A, Tzermiadianos $\mathrm{M}$ : Biomechanics of the posterior lumbar articulating elements. Neurosurg Focus 22(1):E1, 2007

118. Shields LB, Raque GH, Glassman SD, Campbell M, Vitaz T, Harpring J, et al: Adverse effects associated with high-dose recombinant human bone morphogenetic bone protein-2 use in anterior cervical spine fusion. Spine 31:542-547, 2006

119. Siddiqui M, Karadimas E, Nicol M, Smith FW, Wardlaw D: Influence of X Stop on neural foraminal and spinal canal area in spinal stenosis. Spine 31:2958-2962, 2006

120. Smith L: Chemonucleolysis. Clin Orthop Relat Res 67:72-80, 1969

121. Sussman BJ: Inadequacies and hazards of chymopapain injections as treatment for intervertebral disease. J Neurosurg 42:389-396, 1975

122. Tong FC, Cloft HJ, Joseph GJ, Rodts GR, Dion JE: Transoral approach to vertebroplasty for multiple myeloma. AJR Am J Roentgenol 175:1322-1324, 2000

123. Tsuji H: Laminoplasty for patients with compressive myelopathy due to so-called spinal canal stenosis in the cervical and thoracic regions. Spine 7:28-34, 1982

124. Urist MR: Bone: formation by autoinduction. Science 150:893899,1965

125. Urist MR, Huo YK, Brownell AG, Hohl WM, Buyske J, Lietze A, et al: Purification of bovine morphogenetic protein by hydroxyapatite chromatography. Proc Natl Acad Sci U S A 81:371-375, 1984

126. Vasudevan RR, Galvan G, Pait GT, Villavicencio AT, Bulsare KR: Muscle splitting approach with MetrX system for removal of intrathecal bullet fragment: a case report. J Trauma 62:12901291,2007

127. Venable CS, Stuck WG: Electrolysis-controlling factor in the use of metals in treating fractures. JAMA 3:349, 1939

128. Wannamaker GT: Spinal cord injuries: a review of the early treatment in 300 consecutive cases during the Korean Conflict. J Neurosurg 11:517-524, 1954

129. Wang MY, Green BA, Coscarell E, Baskaya MK, Levi AD, Guest JD: Minimally invasive cervical expansile laminoplasty: an initial cadaveric study. Neurosurgery 52:370-373, 2003

130. Wang MY, Prusmack CJ, Green BA, Gruen JP, Levi AD: Minimally invasive lateral mass screws in the treatment of cervical facet dislocations: technical note. Neurosurgery 52:444448, 2003

131. Watters WC, McGirt MJ: An evidence-based review of the literature on the consequences of conservative versus aggressive discectomy for the treatment of primary disc herniation with radiculopathy. Spine J 9:240-257, 2008

132. Williams RW: Microlumbar discectomy: a conservative surgical approach to the virgin herniated lumbar disc. Spine 3:175-182, 1978

133. Wiltse LL, Spencer CW: New uses and refinements of the paraspinal approach to the lumbar spine. Spine 13:696-706, 1988

134. Wong WH, Reiley MA, Garfi SR: Vertebroplasty/kyphoplasty. J Women's Imaging 2:117-124, 2000 


\section{Minimally invasive spine technology and surgery}

135. Yaşargil MG: Microsurgical operation of herniated lumbar disc. Adv Neurosurg 4:81, 1977

136. Young S, Veerapen R, O'Laoire SA: Relief of lumbar canal stenosis using multilevel subarticular fenestrations as an alternative to wide laminectomy: preliminary report. Neurosurgery 23:628-633, 1988

137. Zhou JL, Liu SQ, Ming JH, Peng H, Qiu B: Comparison of therapeutic effect between percutaneous vertebroplasty and kyphoplasty on vertebral compression fracture. Chin J Traumatol 11:42-44, 2008

138. Zucherman JF, Zdeblick TA, Bailey SA, Mahvi D, Hsu KY,
Kohrs D: Instrumented laparoscopic spinal fusion. Preliminary results. Spine 20:2029-2035, 1995

Manuscript submitted May 18, 2009.

Accepted July 8, 2009.

Address correspondence to: Jeffrey H. Oppenheimer, M.D., Central Arkansas Veterans Hospital, LR/112, 4300 West 7th Street, Little Rock, Arkansas 72205-5484. email: jeffrey.oppenheimer@ va.gov. 